\title{
SARS-COV-2: UM VÍRUS CAPAZ DE CONTAMINAR A DEMOCRACIA REPRESENTATIVA E DEBILITAR OS DIREITOS E GARANTIAS FUNDAMENTAIS?
}

\author{
Sérgio Augusto Veloso Brasil* \\ Meire Aparecida Furbino Marques ${ }^{* *}$

\section{RESUMO}

O objetivo deste artigo é estudar a crise na proteção dos direitos e garantias fundamentais, diante da pandemia de Covid-19. O avanço da pandemia tem acentuado a fragilidade nas relações entre eleitores e eleitos, constatando-se uma fracassada democracia representativa com direitos e garantias fundamentais relativizados por medidas administrativas implementadas pelos governantes. A metodologia utilizada foi a revisão de literatura nacional e estrangeira e pesquisa bibliográfica. Conclui-se que há falhas na democracia representativa com eleitos que não respeitam os limites de seus mandatos.

Palavras-chave: Direitos e garantias fundamentais. Covid-19. Democracia representative. Governos populistas. Crise sanitária.

\section{SARS-COV-2: A VIRUS CAPABLE OF CONTAMINATING REPRESENTATIVE DEMOCRACY AND WEAKENING FUNDAMENTAL RIGHTS AND GUARANTEES?}

\begin{abstract}
The objective of this article is to study the crisis in the protection of fundamental rights and guarantees, in the face of the Covid-19 pandemic. The advance of the pandemic has

\footnotetext{
Mestre em Direito Empresarial pela Facudade de Direito Milton Campos. Doutorando em Direito Público pela PUC Minas. Advogado. Currículo Lattes: CV http://lattes.cnpq.br//0281180381209568 ORCID: ID https://orcid.org/0000-0003-3905-5570 E-mail: sergioavbrasil@gmail.com

** Doutoranda e Mestre Direito Público PUC-MG. Especialista Direito Público e Tributário. Prof. Universitária. Membro do Grupo de Pesquisa "Direito, Racionalidade e Inteligência Artificial" UnB. CV http://lattes.cnpq.br/2767731526290041. ORCID: ID https://orcid.org/0000-0003-4463-9554. E-mail: meirefurbino@gmail.com
} 
accentuated the fragility of the relations between electors and elected officials, confirming a failed representative democracy with fundamental rights and guarantees relativized by administrative measures implemented by rulers. The methodology used was a review of domestic and foreign literature and literature search. It is concluded that there are flaws in representative democracy with elected officials who do not respect the limits of their mandates.

Keywords: Fundamental rights and guarantees. Covid-19. Representative democracy. Populist governments. Health crisis.

\section{INTRODUÇÃO}

No Brasil, a Constituição Federal de 1988 representa um avanço em termos de democracia. O Estado brasileiro é democrático e de direito e tem fundamentos importantes: a soberania, a cidadania, a dignidade da pessoa humana, os valores sociais do trabalho, a livre iniciativa e o pluralismo político ${ }^{1}$. A democracia brasileira é também representativa e semidireta $^{2}$. O povo elege seus representantes e delega decisões para que se cumpra o mandato com base na Constituição, que rege os direitos e deveres do cidadão ${ }^{3}$. O poder emana do povo e os cidadãos devem estar vigilantes quanto à movimentação de grupos de poder que projetam seus interesses nas eleições, em detrimento da população.

Em tese, a democracia representativa no Brasil está adequada ao seu território continental e população que passa de 212 milhões de habitantes ${ }^{4}$. No entanto, as condições desiguais em que os cidadãos convivem no país e, ainda, o incentivo econômico que

\footnotetext{
${ }^{1}$ Conforme verifica-se no caput e incisos do Art. $1^{\circ}$ da CRFB/88 (BRASIL, 1988).

${ }^{2}$ A democracia tem origem grega: demos (povo) e kratos (poder). A ideia inicial da cidadania criada pelos gregos vincula-se àquele que fosse considerado cidadão e pudesse exercer o seu poder de participar da política da cidade. Divide-se nos seguintes tipos: a) democracia direta: viável com número reduzido de cidadãos que pudessem participar diretamente da proposta legislativa e votarem nas propostas de leis dos outros cidadãos, como em Atenas; b) democracia participativa: há eleições em que os cidadãos escolhem e nomeiam membros do Executivo e Legislativo, mas as decisões são tomadas pelos cidadãos, por meio da participação e autorização e, c) democracia representativa: é a mais comum nos países republicanos do mundo contemporâneo, em que há vastos territórios e inúmeros cidadãos. As democracias representativas são orientadas por constituições que estabelecem um Estado Democrático de Direito e que regem os direitos e deveres do país. Também chamada indireta ou semidireta pelo fato da participação política ser exercida por meio de representações (PORFÍRIO, 2021).

${ }^{3} \mathrm{O}$ parágrafo único do Art. $1^{\circ}$ da CRFB/88 assim prevê: "Todo o poder emana do povo, que o exerce por meio de representantes eleitos ou diretamente, nos termos desta Constituição" (BRASIL, 1988).

${ }^{4}$ O Brasil é o maior país da América do Sul, com $8.515 .767 .049 \mathrm{~km}^{2}$ de território (INSTITUTO NACIONAL DE ESTUDOS E PESQUISAS EDUCACIONAIS ANÍSIO TEIXEIRA, 2020).
} 
algumas oligarquias utilizam para perdurarem no poder ${ }^{5}$, causam uma grande interrogação sobre a efetividade da democracia representativa, principalmente dos dispositivos constitucionais de controle dos mandatos dos eleitos, e, inclusive, de sanção aos eleitos irresponsáveis que agem com arbitrariedade.

O Estado, enquanto organização política, é composto por território, povo e poder político, tem na Constituição Federal a garantia de respeito dos direitos e garantias fundamentais do cidadão.

Em situação de anormalidade extrema, como uma pandemia, uma catástrofe ou ainda, exemplificativamente, um grave distúrbio da ordem, como uma guerra, poderão ocorrer limitações constitucionais para preservar um bem maior, como a vida ou a integridade das pessoas. Os referidos limites impostos pelos governantes às disposições constitucionais e a elaboração de atos normativos decorrentes para contenção de um estado pandêmico, como o atual, não podem, todavia, servir como fundamento para que a Constituição seja posta de lado, com inovações legislativas amoldadas a um Estado de Exceção.

A dignidade do homem é princípio norteador, a qualquer tempo, e não pode padecer de uma visão política descompromissada do governante ou legislador eleitos que não atendam aos interesses do povo. As medidas administrativas impostas pelos governos, muitas vezes necessárias, resultam da ponderação dos interesses público e privado sob o âmbito constitucional. $O$ interesse público na pandemia é o de preservar a vida e a integridade física dos cidadãos, sem reduzir totalmente o conteúdo mínimo de direitos ou garantias fundamentais e, tampouco, prejudicar a dignidade humana.

Ao se implementar políticas de prevenção e combate ao vírus da Covid-19 o governante deve atentar que a economia não se desvencilha da política de saúde adotada, principamente quando se tem em pauta bloqueios e restrições administrativas de funcionamento de serviços não essenciais. As medidas implementadas devem, obrigatoriamente, obedecer a uma razoabilidade e proporcionalidade, e, como dito,

\footnotetext{
5 “....] El quiebre de las democracias, de acuerdo con Linz (1990), se debe a las desigualdades sociales y económicas que prevalece en los países debido a la concentración que existe del poder económico en pocas personas, la dependencia que existe con otros países, los problemas socioeconómicos prevalecientes, así como también debido a la inestabilidad de las instituciones democráticas que permiten la movilización de las masas" (BURGOS, 2015, p. 57).
} 
obedecer a uma ponderação de interesses, sem sucumbir direitos e garantias conquistados historicamente, retrocedendo socialmente.

Um direito social não estará isento a limitações diante de uma grave crise como a que se vivencia atualmente. Mas, o respeito aos direitos humanos é conditio sine qua nom para a sociedade, que até poderá aquiescer sacrifícios em sua liberdade e na ordem comercial e econômica, por exemplo, desde que cientificada da atual situação de risco. Com informação adequada haverá maior resiliência e confiança na atuação de seus representantes e nos atos normativos decorrentes ${ }^{6}$.

O Estado deve estar presente nas ações necessárias, com o uso do poder que lhe foi delegado ${ }^{7}$. Mas esse poder há de ser legítimo e não desvirtuado, ou desconfigurado para um pseudo-virtutem (VELOSO BRASIL, 2020), ou seja, um pseudo-poder para atender a outros interesses, como a manutenção do próprio poder.

Há uma mitigação de direitos e garantias fundamentais em tempos de crise, principalmente por governos populistas, que surgem e aproveitam, rotineiramente, para culpar as elites por não protegem adequadamente o povo. A pandemia causada pela Covid19 foi solo fértil para o aparecimento e fortalecimento de políticos populistas, que aproveitam a situação para difundir a ideia de caos e se apresentarem como salvadores da pátria.

O presente artigo, baseado em revisão de literatura nacional e estrangeira e pesquisa bibliográfica, tem por objetivo estudar a crise na proteção dos direitos e garantias fundamentais, diante da pandemia de Covid-19.

Especificamente objetiva-se analisar o populismo e suas estratégias de governo para o enfretamento da pandemia. Além disso, estudar a democracia representativa e o equilíbrio de poder diante da adoção de medidas de controle de contágio e disseminação da Covid-19.

\footnotetext{
${ }^{6}$ Para Harari (2020, p. 37): "Uma população bem informada agindo por conta própria costuma ser muito mais poderosa e efetiva do que uma população ignorante e policiada. [...]. Considere-se, por exemplo, o hábito de lavar as mãos com sabão". Apenas no século XIX que os cientistas descobriram a importância de fazê-lo. "Hoje bilhões de pessoas lavam as mãos diariamente, não por temerem a polícia do sabão, mas por compreenderem os fatos" (HARARI, 2020, p. 37).

${ }^{7}$ O professor José Afonso da Silva (apud MEDINA, 2012, p. 28) leciona: "Estado é poder soberano que tem por fim específico e essencial a regulamentação global das relações sociais entre os membros de um povo sobre um dado território".
} 
Indaga-se: a democracia representativa e seus governantes estariam preparados para atender os interesses do povo diante da pandemia de Covid-19, preservando os direitos e garantias fundamentais?

A hipótese que se apresenta é que há falhas na democracia representativa nas ações de combate à pandemia de Covid-19. Vislumbram-se poucas soluções para retratação ou punição dos eleitos que não respeitem os limites de seus mandatos e os interesses do povo, ou seja, para aqueles que adotem gestões populistas com ações em interesse próprio ou já capturados pelo poder econômico.

\section{DEMOCRACIA E CONSTITUIÇÃO: NECESSIDADE DE PROTEÇÃO DOS DIREITOS E GARANTIAS FUNDAMENTAIS}

O direito e a política têm uma relação próxima. A democracia, enquanto regime de governo caracterizado pela participação do povo na vida política, pode ter os seguintes tipos: direta, indireta e semidireta. No caso da democracia semidireta (Brasil), há a eleição de representantes políticos, mas os cidadãos podem, ainda, participar da política com consultas públicas ou iniciativas populares (LENZI, 2019). Sempre é bom que o povo, seja em que regime for, esteja atento para que não se torne um instrumento de manipulação do poder no atendimento a interesses de castas e grupos de elite. O povo é o legítimo detentor do poder na democracia - não é massa a ser manobrada com a psicologia do homem, com fins egoísticos.

Os que vivem nos meandros da política conseguem ver janelas de oportunidade que a maioria dos cidadãos, por ausência de educação política, não conseguem ver. No decorrer do tempo, com maior maturidade, conseguem perceber o real significado de manobras políticas das elites quando desencriptam suas reais intenções. Há, pois, uma encriptação do poder na política. Conforme Sanín-Restrepo e Araújo (2020, p. 2): “[...] encriptar (poder) é simular poder (democrático, constituinte) e proibir ou condicionar o ser enquanto colapsa a agência política (poder constituinte, resistência) dentro de estruturas fixas, finais transcendentes e sólidas (poder constituído, o direito)".

Ao se falar de direito e política, destaca-se a Constituição que, nas palavras de Sampaio (2013, p. 13), era “[...] a forma jurídica constitucional, nascida de interpretações sucessivas do Corpus Juris Civilism do direito canônico e comum, era a garantia contra os 
desmandos e os abusos do Estado; era o freio para o exercício da política". Para Sampaio (2013, p. 60), “[...] a normatividade da Constituição foi um dos mais revolucionários processos da história do direito e da política. A política, fonte das normas jurídicas, passou a ser regrada pelo direito". As constituições não se restringem à constituição política ou do Estado tão somente, e, cada vez mais, inserem-se capítulos e artigos que são considerados alicerces para o ordenamento jurídico dos demais ramos do direito, sejam públicos ou privados.

No esteio da ordem jurídica, a lei confere ao agente público poder vinculado e 'poder' discricionário, dessa maneira, em uma de suas classificações doutrinárias, quanto ao grau de liberdade da Administração em sua prática, os atos administrativos podem ser emanados do poder vinculado ou regrado, quando a lei estabelece os requisitos e condições de sua realização, não existindo liberdade de opção para o agente público. Nos atos administrativos praticados em decorrência do exercício do poder discricionário, o governante ou o agente público terá liberdade na escolha do conteúdo, destinatário, conveniência, oportunidade e no modo de execução. Mas, discricionariedade não se confunde com arbitrariedade, pois a decisão deverá ser a melhor opção adotada para o coletivo, uma vez que na decisão adotada ao alvedrio de quem a pratica não se verifica a conveniência e oportunidade daquele ato praticado.

$\mathrm{Na}$ atual pandemia de Covid-19, os governantes e os agentes públicos tiveram que decidir em prol de uma série de medidas administrativas para a prevenção e combate ao contágio do novo coronavírus. Nas três esferas de governo (federal, estadual e municipal) foram expedidos Decretos e Medidas Provisórias, entre outros.

O nascedouro do alerta e recomendações para a crise sanitária mundial teve sede na Organização Mundial de Saúde (OMS), que declarou, em 30 de janeiro de 2020, situação de Emergência de Saúde Pública de Importância Internacional, sendo considerado depois como pandemia, devido ao surto do novo coronavírus. O marco legislativo no Brasil foi a Lei $\mathrm{n}^{\circ}$ 13.979, de 6 de fevereiro de 2020 (COSTA, 2020).

Os governos, diante de uma crise sanitária internacional, necessitaram adotar medidas de emergência para a proteção da coletividade, como isolamento, quarentena, realização obrigatória de exames, testes, vacinas, tratamentos médicos e medidas profiláticas; restrição de locomoção e uso de transportes terrestres, ferroviários e aéreos; requisição de 
bens e serviços de pessoas naturais e jurídicas e autorização excepcional e temporária para importação de produtos sujeitos à vigilância sanitária, entre outras medidas previstas em lei.

O epicentro da pandemia no Brasil foi o Estado de São Paulo, que reconheceu o estado de calamidade pública com o Decreto $\mathrm{n}^{\circ}$ 64.879, de 20 de março de 2020. O Presidente da República editou, na mesma data, a Medida Provisória n 926/2020, que alterou a Lei Federal n 13.979/2020, originando um conflito com os Estados da federação, em relação ao apontamento dos serviços essenciais e quais os serviços públicos não seriam suspensos (COSTA, 2020; MURTA; RAPOSO, 2020). Em imbróglio político e jurídico decorrente de impasse entre União e Estados, o Supremo Tribunal Federal (STF) garantiu que os estados e municípios decidissem sobre o isolamento social e que prefeitos e governadores tivessem autonomia para determinar a intensidade e como se dará o isolamento social.

A atuação de governadores e prefeitos é interdependente das medidas de apoio do Ministério da Saúde e, de forma geral, há uma grande dessintonia entre os níveis de governo, sendo procrastinada a vacinação da população e medidas de prevenção ao contágio do coronavírus, como uso de máscara, isolamento familiar e distanciamento social.

E, nesse cenário, a tecnologia entra em cena no mundo como um marco histórico de inovação e, pode-se dizer, de nova convivência social, no período emergencial. A tecnologia teve larga aplicação em diversas áreas, como na educação (aulas on line, palestras, livros virtuais etc.); na medicina (telemedicina, telediagnóstico etc.); no judiciário (audiências, virtualização dos processos físicos, aprimoramento da tecnologia e da segurança de sistemas etc.); nos negócios e serviços públicos (e-commerce, shop streaming, redes sociais, reuniões on line, home office, teletrabalho etc.); nas comunicações de forma geral (informação pública e comunicação entre membros da família e amigos por vídeo e telefonia celular, uso de redes sociais) (MURTA; RAPOSO, 2020).

Em alguns países, sendo o principal exemplo a China, é aproveitado todo o aparato tecnológico para que possa ter uma maior vigilância e controle populacional com mitigação de direitos e garantias fundamentais como privacidade, liberdade de locomoção, liberdade de expressão, direito do livre exercício do trabalho, entre outros.

No caso do Brasil, a autonomia federativa no enfrentamento da Covid-19 apresenta abusos no poder conferido aos governos locais. Murta e Raposo (2020, p. 18) afirmam que “[...] as autoridades brasileiras, numa situação de calamidade declarada, mas não de Estado de 
exceção, agem de forma desquilibrada, arbitrária e sem orquestração, gerando verdadeiros atentados às próprias autonomias federativas e, por conseguinte, abusando do poder em relação ao cidadão". São gerados conflitos decorrentes da autonomia federativa como, por exemplo, o Estado que interfere no ente Município que, por sua vez, recusa-se a cumprir determinações da União. Há uma ressignificação da interpretação constitucional da autonomia, pois a Corte Suprema reconhece que o interesse local/regional é definidor da legitimidade de atuação do ente municipal ou estadual (MURTA; RAPOSO, 2020).

A relevância da atuação dos municípios relaciona-se à premissa de que a República Federativa do Brasil é formada pela união indissolúvel dos Estados e Municípios e do Distrito Federal e constitui um Estado Democrático de Direito.

No limite da autonomia dos entes, os princípios constitucionais são vilipendiados, isto é, não se observa adequadamente a separação dos poderes, da proporcionalidade, da razoabilidade ou da subsidiariedade, entre outros.

Quando se declara toque de recolher em cidades; monitora o cidadão pelo seu celular; aplica multa e voz de prisão para o cidadão que está fora de sua casa e não usa máscara; fecha entrada de cidades para constranger visitantes; encerra atividades empresariais indefinidamente; diminui oferta de transporte público, impedindo mobilidade; cria regras para multar pessoas que celebrem festas em suas casas; ameaça a população com os rigores da lei, se não permanecerem em cárcere privado, alguma coisa está fora da ordem.

As arbitrariedades são latentes, sob o pretexto nobre de combate à pandemia. No entanto, falta bom senso, proporcionalidade (MURTA; RAPOSO, 2020, p. 19-20).

O que se pode verificar é que não há uma política nacional, e talvez nem mesmo internacional, efetiva para o combate ao novo coronavírus. Não há lideranças suficientemente fortes que possam agregar Estado, cientistas e sociedade empresária no combate a Covid-19, infelizmente.

A democracia representativa fracassa à medida que os eleitos não conseguem atender à demanda geral por saúde. Instala-se uma crise sanitária, com evidente desequilíbrio entre os poderes. "A ausência de uma concertação liderada pelo governo federal e apoiada pelos demais entes no combate à pandemia, criou um cenário de conflitos políticos e com diversos efeitos colaterais sobre a população" (MURTA; RAPOSO, 2020, p. 33).

Há, ainda hoje, inúmeros conflitos internos entre os poderes Executivo, Legislativo e Judiciário e entre os níveis de governo, enfraquecendo-se a democracia e o respeito aos direitos e garantias fundamentais previstos na Constituição Federal. Enfim, o resultado é 
lamentável e catastrófico. Na adoção de medidas arbitrárias para o enfrentamento da Covid19, com desprezo de direitos e garantias constitucionais, destaca-se a atuação de governos populistas que adotam medidas administrativas prejudiciais ao cidadão. Mas, afinal o que seria o populismo?

\title{
3 O POPULISMO E MEDIDAS ADMINISTRATIVAS DIANTE DA PANDEMIA DE COVID 19
}

O termo populismo caracteriza uma série de manifestações sociais distintas ao longo da história. Debert (2008, p. 14) deduz que “ [...] não são as bases sociais dos movimentos que os identifiquem como populistas". Ao tentar definir o termo leciona que o populismo aparece como expressão de camadas sociais distintas, como, por exemplo: a) o movimento russo narodinik, considerado como manifestação de uma ideologia camponesa; b) o populismo norte-americano que expressa uma ideologia de mobilização típica de pequenos proprietários rurais que se opõem à vida e ao grande capital; e c) o populismo na América Latina, que é uma manifestação urbana, considerado como expressão política e ideológica da pequena burguesia e dos setores marginais (DEBERT, 2008). Há uma segunda solução apresentada por Debert (2008, p. 15), que caracteriza o populismo não “ [...] como um movimento mas como uma ideologia, cujos traços dominantes seriam: anti-status, apelo ao povo e não às classes, desconfiança dos políticos tradicionais, anti-intelectualismo, etc.”.

Nessa linha da história, da filosofia e da geopolítica, Zanatta (2014), por sua vez, diz que a atuação do populismo no mundo não tem raízes profundas e caracteriza-se pela contraposição à modernidade, que tem uma visão de mundo hostil. Assim,

\begin{abstract}
Desde Rusia hasta los Estados Unidos del siglo XIX pasando por la Europa balcánica y latina, desde Canadá hasta América Latina y en muchas realidades del mundo islámico actual, el populismo y su vsión del mundo son enconados adversiros de la idea ilustrada de la modernidad. O sea de una idea basada en el individuo, en la razón y en la heterogeneidad fisiológica de las sociedades humanas. Precisamente, porque está anclada en una visión del mundo hostil a la ilustrada, no seria correcto decir que la populista tiene raíces profundas y goza de buena salud en todas partes del mismo modo (ZANATTA, 2014, p. 11-2).
\end{abstract}

O aludido professor de História da América Latina da Universidade de Bologna indaga: “Em qué consiste el 'duro núcleo' del populismo”? Afirma, então, que o cerne do populismo como ideologia é indefinido e não 'formalizado' como as grandes ideologias dos 
séculos XIX e XX. "Não há um manual do bom populista ou um filósofo a quem se possa recorrer" (ZANATTA, 2014, p. 20). Diz ainda que não se pode negar que o populismo varia de muitos modos, seja em um sentido mais reacionário ou, então, progressista, seja o termo de direita ou de esquerda (ZANATTA, 2014).

Tampouco nega-se que o populismo, tratando-se de ideologia, possa ser colonizado por outras ideologias mais estruturadas. Encontra-se o cerne da ideologia populista em um corpo fascista ou comunista, reacionário ou revolucionário, clérico ou anticlérico e assim por diante. Há uma grande permeabilidade. Nenhuma ideologia gira apenas em torno de um núcleo totalmente racional e formalizado, mas é também constituída por elementos emocionais e simbólicos. Aceita-se que as ideologias servem para expressar interesses ou resolver tensões com os instrumentos que a história e a vida colocam à disposição, especialmente quando aquelas vigentes parecem ter parado de funcionar, então, não há dúvida: o populismo é uma ideologia ${ }^{89}$ (ZANATA, 2014).

Para entender melhor o populismo, Zanata (2008) cita Isaiah Berlin ${ }^{10}$, que apresenta seis pistas principais para responder em que consiste o núcleo principal do populismo:

a) não é uma ideologia individualista, mas sim, comunitária;

b) é apolítico, senão, antipolítico, dado que os valores sobre os quais se inspiram e nos quais se baseia dizem respeito à esfera social e somente a ela;

\footnotetext{
8 “O conceito de ideologia está relacionado a um conjunto de crenças políticas, econômicas e sociais. É comum encontrar sua definição como um 'conjunto de ideias', ou seja, uma ideologia nada mais é do que as ideias sustentadas por um grupo de pessoas, ou apenas por uma pessoa que tem certa visão sobre determinado assunto" (IDEOLOGIA, [201-?].

9 "Desde luego, nadie niega que el populismo como ideologia sea indefinido y no "formalizado" como las grandes ideologias de los siglos XIX y XX: esto es, que no se encontrará el manual del buen populista o el filósofo que ha dado origen al populismo, y a cuya fuente acuden los populistas. Tampoco se puede negar que esto hace al fenòmeno variable en diversos modos, sea en un sentido más reaccionario o en un sentido más progresista, sea de derecha o de izquierda, ni que pueda ser colonizado por otras ideologias más estructuradas que engloban su "núcleo en una apariencia tan inconsistente. Como se verá, en ese caso será fácil encontrar el corazón de la ideologia populista en um "cuerpo" fascista o comunista, reaccioario o revolucionario, clerical o anticlerical y así sucesivamente. No obstante, esto no deberia inducir a ignorar el sdimento más profundo. Al contrario, deberia convencer de su gran permeabilidad. Por otra parte, ninguna ideologia gira solo en torno a un núcleo totalmente racional y formalizado, sino que también está formada por elementos emotivos y simbólicos. $\mathrm{Si}$, además, se acepta que las ideologias sirvem para expresar intereses o resolver tensiones con los instrumentos que la historia y la vida pondem a su disposición, em especial cuando aquellos vigentes parecen haber dejado de funcionar, entonces no caben dudas: el populismo es una ideologia" (ZANATA, 2014, p. 20 1).

${ }^{10}$ Filósofo, historiador de ideias, também reconhecido por suas palestras, ensaios e suas conversas. Nasceu na Rússia e foi para a Inglaterra e naturalizou-se britânico. Ele era conhecido por seu brilho de conversação, sua defesa do liberalismo e do pluralismo, sua oposição ao extremismo político e fanatismo intelectual e seus escritos acessíveis e brilhantes sobre pessoas e ideias (ISAIAH BERLIN, 2020).
} 
c) incorpora uma aspiração à regeneração baseada na vontade de restaurar ao povo a centralidade e a soberania que foram roubadas dele;

d) pretende transplantar os valores de um mundo do passado, que idealiza como um mundo de harmonia e igualdade social para a situação atual: torna-se hoje para purificar o mundo moderno;

e) é persuadido a abordar a maioria das pessoas ou, nos casos mais extremos, à sua totalidade;

f) tem essa visão que tende a emergir em sociedades que estão em uma fase delicada e, muitas vezes, convulsiva de modernização ou transformação.

E, afinal, para efeitos deste estudo, diante da pandemia de Covid-19, questiona-se como está acontecendo a atuação de governos populistas e não populistas?

\subsection{Populismo e pandemia do novo coronavírus}

Em pesquisa realizada durante a pandemia de Covid-19, por Bayerlein e Gyöngyösi (2020), do Departamento de Ciência Política da Universidade de Kiel e do Instituto de Economia Mundial de Kiel na Alemanha, verifica-se que os governos não populistas tiveram um aumento na popularidade e os populistas usaram a crise para ampliar seus poderes no sistema político.

Os populistas separam a sociedade em grupos antagônicos, quais sejam 'o povo bom' e a 'elite corrupta' e afirmam representar a vontade geral do povo. Verifica-se que os governos populistas, provavelmente, não serão enfraquecidos pela crise de Covid-19 e uma grave crise econômica pode levar a uma onda de atores populistas para o governo. Essa definição implica que o populismo é menos uma ideologia e mais um estilo político. Embora esse estilo seja freqüentemente usado para descrever partidos e candidatos da oposição, também é comumente encontrado entre governos (BAYERLEIN; GYÖNGYÖSI, 2020).

Ao se comparar as políticas de confinamento implementadas por governos populistas e não populistas, concluiu-se que estas foram muito semelhantes, com medidas desde o fechamento de escolas até a proibição de reuniões públicas e restrições a viagens. Os Estados Unidos e o Reino Unido ficaram para trás na resposta imediata, mas 
alcançaram outros países. Outros países governados por populistas como Polônia, Hungria e Índia implementaram medidas rapidamente (BAYERLEIN; GYÖNGYÖSI, 2020).

A amostra dos pesquisadores incluíram na pesquisa, intitulada The impact of Covid-19 on populism: will it be weakened?, um total de 14 países com base no tamanho e extensão da crise no país, quais sejam: Áustria, Brasil, Canadá, França, Alemanha, Hungria, Índia, Itália, Japão, México, Polônia, Espanha, Reino Unido, Estados Unidos. Os governos populistas foram do Brasil, Hungria, Índia, Polônia, Reino Unido e Estados Unidos. O único populista no governo cujo apoio da população cresceu fortemente durante a crise foi o de Boris Johnson, no Reino Unido. No Brasil, o governo Bolsonaro despencou seu apoio popular (BAYERLEIN; GYÖNGYÖSI, 2020) ${ }^{11}$. Não há como se atribuir a crise da Covid-19 ao fracasso das 'elites' ou a algum subgrupo identificável da população.

Outro dado interessante é que cinco entre os seis governos considerados populistas introduziram leis que representam um risco médio ou alto para as instituições democráticas, podendo-se citar as ações da Índia, em que a legislatura foi suspensa indefinidamente; da Hungria, em que o governo pode governar por decreto; da Polônia, em que se implementou uma nova lei estendendo o estado de emergênia além do limite permitido pela constituição; dos EUA, em que Trump contornou indefinidamente as restrições legais aos seus poderes executivos sem a aprovação do Congresso; do Brasil, em que suspendeu-se o direito constitucional de receber informações solicitadas do governo; da Hungria, em que o governo se reservou o direito de determinar o que é uma 'desinformação' punível. Enfim, apenas na Inglaterra foi que as leis de emergência do governo Boris Johnson foram consideradas como baixo risco (BAYERLEIN; GYÖNGYÖSI, 2020).

A escala global do desafio causado pelo surto de Covid-19 é uma marca sem precedentes para as democracias contemporâneas, que apresentam soluções locais pelos governos dos países e seus entes federativos. Constata-se que a coordenação global é extremamente fraca, sem lideranças e com acentuada busca pela hegemonia e corrida pela sobrevivência dos países de primeiro mundo.

\footnotetext{
11 “[...] In fact, the only populist in government whose support grew strongly during the crisis is Boris Johnson in the UK. Contrary to that, the support for Brazil's Jair Bolsonaro plummeted after the outbreak. Other populist leaders, like Donald Trump, Narendra Modi, Viktor Orbán, and the governing Polish PiS party witnessed only minor increases in their popular support" (BAYERLEIN, GYÖNGYÖSI, 2020, p. 92).
} 
A pandemia de Covid-19 causou também uma discussão sobre o equilíbrio de poder federal, estadual e municipal. Na Alemanha, em uma pesquisa de Tepe et al. (2020), com quase 2.000 entrevistados, constatou-se que há apoio dos cidadãos a medidas como lockdown imposto pelos governos em uma tentativa de salvar vidas durante a pandemia. Há aceitação da transferência do poder dos parlamentos para os governos, trocando o imperativo maximalista do Estado e aceitando perdas na riqueza econômica ou nas liberdades civis, em longo prazo, em prol de uma garantia de proteção da vida pelos governos. Referidas medidas que afetaram as perdas econômicas tiveram menos apoio especialmente entre os jovens entrevistados (TEPE et al., 2020).

Na Espanha, de 20 a 28 de março de 2020, em pesquisa de Amat et al. (2020), em período compreendido antes e depois do início do surto do vírus, obteve-se resultados de preferência dos pesquisados por soluções nacionais para as alternativas dos governos no uso de poderes excepcionais para impor bloqueios com o sacrifício de liberdades civis e alterações no equilíbrio de poder pré-existente, com temor por uma virada autoritária. Constatou-se demanda generalizada por uma liderança forte, uma disposição de renunciar à liberdade individual e tendência em apoiar uma governança tecnocrática (AMAT et al., 2020).

No Brasil, o poder judiciário, com decisão do STF, manifestou recentemente que os estados e municípios, no âmbito de suas competências e em seus territórios, podem adotar medidas de restrição à locomoção intermunicipal e local durante o estado de emergência decorrente da pandemia do novo coronavírus, sem a necessidade de autorização do Ministério da Saúde para a decretação de isolamento, quarentena e outras providências (STF..., 2020).

São muitas mudanças e transformações no exercício do poder em tempos de constitucionalismo democrático. A Constituição continua sendo a referência dos atos administrativos de seus governantes, mas é preciso que não fique em desuso ou que seja desconfigurada para servir às elites ou a governos populistas e oportunistas.

\section{DIREITO À SAÚde E POLÍTICA PÚBLICA}

Barroso (2002) descreve que a Constituição contemporânea (ou neoconstitucionalismo ou novo direito constitucional) identifica um conjunto amplo de 
transformações ocorridas no Estado e no direito constitucional, como formação do Estado constitucional de direito, consolidada ao longo das décadas finais do século XX (marco histórico); o pós-positivismo, com a centralidade dos direitos fundamentais e a reaproximação do Direito e ética (marco filosófico); e ainda, o conjunto de mudanças que incluem a força normativa da Constituição, a expansão da jurisdição constitucional e o desenvolvimento de uma nova dogmática da interpretação constitucional (marco teórico).

Nesse período de 'praga centenária'12 é, ainda mais, necessário repensar o constitucionalismo democrático como resposta aos conflitos que ameaçam a democracia e a Constituição, quando os cidadãos são tolhidos em seus direitos e garantias fundamentais, sob pena de se perder a segurança jurídica e dar espaço a regimes opressores nos diversos níveis da federação.

O garantismo constitucional impõe ao Estado a obrigação - o dever - de respeito aos direitos humanos como garantia da própria Constituição. Após a segunda guerra mundial consolidou-se um intenso movimento em prol dos direitos humanos, com preocupação pela própria existência da humanidade.

A Constituição da Organização Mundial da Saúde (OMS), de 1946, em seu preâmbulo apresenta princípios relevantes, dos quais destacam-se:

\footnotetext{
A saúde é um estado de completo bem-estar físico, mental e social, e não consiste apenas na ausência de doença ou de enfermidade.

Gozar do melhor estado de saúde que é possível atingir constitui um dos direitos fundamentais de todo o ser humano, sem distinção de raça, de religião, de credo político, de condição econômica ou social.

A saúde de todos os povos é essencial para conseguir a paz e a segurança e depende da mais estreita cooperação dos indivíduos e dos Estados.

Os resultados conseguidos por cada Estado na promoção e proteção da saúde são de valor para todos.

$\mathrm{O}$ desigual desenvolvimento em diferentes países no que respeita à promoção de saúde e combate às doenças, especialmente contagiosas, constitui um perigo comum.

$[\ldots]$
}

\footnotetext{
${ }^{12}$ Conforme Harari (2020, p.60) “[...] não testemunhamos uma epidemia global nessas proporções em pelo menos cem anos". Ainda explicou que "Nos cem anos que se passaram desde 1918, a humanidade ser tornou ainda mais vulnerável a epidemias graças a uma combinação de crescimento populacional e maior eficácia dos transportes. [...] Contudo, tanto a incidência quanto o impacto das epidemias decresceram [...] a melhor defesa que os humanos têm contra os patógenos não é o isolamento, mas a informação. A humanidade tem vencido a guerra contra as epidemias porque, na corrida armamentista entre patógenos e médicos, os patógenos dependem de mutações cegas, ao passo que os médicos se apoiam na análise científica da informação" (HARARI, 2020, p. 14-5).
} 
Os Governos têm responsabilidade pela saúde dos seus povos, a qual só pode ser assumida pelo estabelecimento de medidas sanitárias e sociais adequadas (OMS, 1946).

Posteriormente à Constituição da OMS, de 1946, há várias normas que tratam da saúde no mundo e que impactam na melhor qualidade de vida em sociedade e, para fins do presente estudo, cita-se Alves e Resende (2020, p. 69) e uma breve remissão histórica realizada pelos autores:

a) em 1948 há a proclamação da Declaração Universal dos Direitos Humanos, no âmbito da Organização das Nações Unidas (ONU), que prevê que todo ser humano tem "[...] o direito a um padrão de vida capaz de assegurar-lhe, e a sua família, saúde e bem-estar";

b) em 1966 há o Pacto Internacional de Direitos Econômicos, Sociais e Culturais, que declara o "[...] direito de toda pessoa desfrutar o mais elevado nível possível de saúde física e mental";

c) em 1978, a Declaração de Alma-Ata em que se previu a "[...] urgência de se promover a saúde de todos os povos", e ainda estabeleceu que "[...] a promoção e proteção da saúde dos povos é essencial para o contínuo desenvolvimento econômico e social e contribui para a melhor qualidade de vida e para a paz mundial";

d) no Brasil, em 1986, ocorreu a VIII Conferência Nacional de Saúde (CNS) que foi um marco histórico, influenciado principalmente pela Declaração de Alma-Ata.

Há, pois, um conceito dinâmico da saúde, examinado no contexto histórico e de acordo com diferentes fatores socioeconômicos, ambientais, geográficos etc., variando no tempo e no espaço, sendo necessárias adequações a serem feitas pelo estudioso e pela autoridade sanitária para aplicação do direito à saúde (ALVES; RESENDE, 2020).

No artigo 196 da Constituição da República Federativa do Brasil de 1988 há a previsão de que "[...] a saúde é direito de todos e dever do Estado, garantido mediante políticas sociais e econômicas que visem à redução do risco de doença e de outros agravos e ao acesso universal e igualitário às ações e serviços para sua promoção, proteção e recuperação" (BRASIL, 1988).

O STF, no Brasil, em ADI no 3.510 e em vários outros momentos, manifestou-se sobre o Direito à saúde, como um dos primeiros e mais relevantes direitos sociais de natureza 
fundamental (art. $6^{\circ}$ da CF) e também como o primeiro dos direitos constitutivos da seguridade social (caput do art. 194 da CF) (MEDINA, 2012).

Reportando aos tempos atuais de pandemia de Covid-19, pode-se afirmar que, se antes já era difícil aos governos administrar os parcos recursos para atender a uma saúde pública eficiente sem apoio da rede particular, em que pese a obrigação do Estado, atualmente a questão está fora de controle. Basta verificar o registro de 351.334 óbitos no Brasil devido a Covid-19, que fica apenas após os Estados Unidos da América que tem o registro de 555.712 óbitos. O Brasil tem a triste estatística de segundo lugar no mundo, ficando à frente de países como México (209.212), Índia (170.179), Reino Unido (127.087) e Itália (114.254), conforme dados da OMS, em 12 de abril de 2021 (WORLD HEALTH ORGANIZATION, 2021).

Em termos de prevenção, se considerar o número de doses que cada país aplicou no mundo, o Brasil está em quinto lugar no ranking global, conforme dados oficiais compilados pela Universidade de Oxford (MAGENTA, 2021). Por outro lado, se for considerado o tamanho da população do Brasil, com 212 milhões de habitantes, este aparecerá em $73^{\circ}$ lugar entre 166 nações e territórios. Prudente afirmar que a vacinação, por si só, não é garantia de superação do período pandêmico. Sequer os integrantes dos grupos de risco foram imunizados, imagine o restante da maioria da população que não tem nem previsão de data em que será vacinada.

Para que as medidas administrativas desenvolvidas pelos governantes sejam razoáveis, proporcionais e devidamente fundamentadas, a Constituição será referência para se evitar ilegalidades e injustiças e violar os direitos humanos e, em especial, a própria Constituição e os direitos e garantias fundamentais nela esculpidas.

A atuação dos poderes executivo, legislativo e judiciário deve buscar um equilíbrio do poder uno. O mecanismo de "[...] freios e contrapesos", “[...] atribuindo-se a uns, embora restritamente, funções que em tese corresponderiam a outros, pretende-se promover um equilíbrio melhor articulado entre os chamados 'poderes', isto é, entre os órgãos do Poder, pois, na verdade, o Poder é uno" (BANDEIRA DE MELLO, 2012, p. 143).

A Comissão Interamericana de Direitos Humanos editou a Resolução no 01/2020, em 10 de abril de 2020, com recomendações de isolamento social e medidas protetivas para o combate à pandemia para os países signatários (ORGANIZAÇÃO DOS ESTADOS AMERICANOS, 2020). 
Os direitos e liberdades previstos na magna Carta não são absolutos, mas o relativismo imposto pelos governantes em momento de pandemia não podem ser usados como manobra de poder na adoção de medidas administrativas arbitrárias, sem consulta popular, uma vez que a força normativa que detém a Constituição poderá arguir a devida inconstitucionalidade do ato praticado.

Medidas de boas práticas devem ser mantidas ou implementadas pelos governos e sociedade civil organizada, como: a) incrementar exponencialmente a vacinação pelos setores público e privado; b) investir na formação de profissionais de saúde, em cientistas, em empresas e indústrias de fabricação de insumos, medicamentos e equipamentos de saúde; c) adotar uma vigilância sanitária nacional (isolamento familiar, distanciamento social, uso de equipamentos de proteção individual e assepsia em todas instalações públicas e privadas); d) aumentar a testagem em possíveis infectados; e) rastrear os infectados e incrementar o apoio nos locais de maior infecção; f) auxílio econômico, fiscal e isenção de taxas e impostos para população mais necessitada e para hospitais e clínicas de saúde.

\section{CONCLUSÃO}

A solidariedade, harmonia e boa convivência do homem estão pautadas em regras sociais que, muitas vezes, culminaram, historicamente, na estruturação do ordenamento jurídico vigente, e que tem na força normativa da Constituição a garantia da manutenção e preservação do Estado de Direito Democrático e, portanto, da preservação do pacto entre o povo e seu(s) governante(s), ou seja, entre eleitor e eleito. Esta representação política está configurada em dois polos: o representado e o representante. Assim, é essencial a interrelação do titular do poder político, que é o povo, com seus representantes temporários que exercem aquele poder delegado.

A democracia, como regime de governo, elege representantes do povo e que exercerão o poder em nome deste. $\mathrm{O}$ eleito tem o dever de agir conforme o interesse público e a vontade da coletividade e ponderar as medidas que serão impostas. A participação popular deve ser incrementada nas decisões que se espraiam no mundo político sem um filtro e que geram insatisfação diante das arbitrariedades, senão ilegalidades, cometidas. 
Em tempos de pandemia de Covid-19, governos, na maioria populistas, utilizam poderes excepcionais para impor bloqueios, sacrificando-se direitos e garantias fundamentais, e ainda, com risco de uma virada autoritária. O equilíbrio de poder está impactado e inúmeras propostas de auxílios à população menos favorecida são apresentadas por todo o mundo, devido às consequências econômicas e sociais dos referidos bloqueios.

Além do cômputo das mortes e descontrole sanitário vigente, com ondas de crise da pandemia do novo coronavírus, inicia-se uma grave recessão, com fechamento de empresas, perda e diminuição da oferta de postos de trabalho, aumento de desempregados e trabalhadores informais, perda do poder aquisitivo, aumento do número de pessoas que dependem de apoio para alimentos, abrigo, medicamentos e assistência à saúde.

Os impactos psico-físiológicos nas pessoas são incontroversos. A retomada da confiança na vida em sociedade e a readequação do atual modelo de gestão políticoeconômico-social da humanidade são inquestionáveis. Trata-se de uma virada de época que apenas se iniciou.

A tecnologia está em patamar de destaque e pode vir a ser um auxiliar para a solução de vários problemas, mas deve ser acompanhada para que não se torne aliada de eleitos populistas e ditadores.

Enfim, espera-se da democracia representativa que os governantes eleitos pelo povo atendam aos interesses da coletividade, evitando interesses pessoais e injustiça. Deve-se respeitar o mandato que lhes foi concedido nas eleições para a defesa e preservação dos direitos e garantias fundamentais, evitando-se medidas administrativas sem a participação popular. Daí, a resistência aos privilégios dos 'mais inteligentes', com uma nova insurreição libertária ao regime de opressão e injustiça que se instala. O poder não fica quieto, sempre quer aparecer de alguma maneira.

\section{REFERÊNCIAS}

ALVES, Cândice L.; RESENDE, José Renato. A emergência de um Direito Sanitário Democrático. In: REZENDE, Elcio Nacur et al. (orgs.). Implicações jurídicas do Covid-19. Belo Horizonte: Arraes Editores, 2020. p. 67-83. 
AMAT, Francesc et al. Pandemics meet democracy: Experimental evidence from the COVID-19 crisis in Spain. April 5, 2020. Disponível em: https://osf.io/dkusw/download. Acesso em: 21 dez. 2020.

BANDEIRA DE MELlO, Celso Antônio. Curso de Direito Administrativo. São Paulo: Malheiros, 2012.

BARROSO, Luis Roberto. Temas de direito constitucional. 2. ed. Rio de Janeiro: Renovar, 2002.

BAYERLEIN, Michael; GYÖNGYÖSI, Gyöizö. The impact of Covid-19 on populism: will it be weakened? June 2020. Disponível em: https://www.ifw-

kiel.de/fileadmin/Dateiverwaltung/IfW-

Publications/Michael_Bayerlein/Impact_Covid_19_on_Populism_Bayerlein_et_al_6_2020.pd f. Acesso em: 20 dez. 2020.

ISAIAH BERLIN. In: STANFORD Encyclopedia of Philosophy, 2020. Disponível em: https://plato.stanford.edu/entries/berlin/. Acesso em: 2 abr. 2021.

BRASIL. [Constituição (1988)]. Constituição da República Federativa do Brasil. 1988.

Disponível em: http://www.planalto.gov.br/ccivil_03/constituicao/constituicaocompilado.htm. Acesso em: 3 abr. 2021.

BURGOS, Karla R. Democracia y tipos de democracia. 2015. Disponível em: http://eprints.uanl.mx/8477/1/Documento2.pdf. Acesso em: 1 abr. 2021.

COSTA, Aline Raquel Gonçalves. Impacto da Pandemia da Covid-19 no Brasil e uma Leitura dos seus Reflexos na Aceleração Abrupta à Adesáo ao Mundo Virtual e das Relações Jurídicas Sociais e Comerciais Nacionais e Internacionais. In: REZENDE, Elcio Nacur et al. (orgs.). Implicações jurídicas do Covid-19. Belo Horizonte: Arraes Editores, 2020. p. 1-12.

DEBERT, Guita G. Ideologia e populismo: Adhemar de Barros, Miguel Arraes, Carlos Lacerda, Leonel Brizola. Rio de Janeiro: Centro Edelstein de Pesquisas Sociais, 2008.

HARARI, Yuval Noah. Notas sobre a pandemia: e breves lições para o mundo do póscoronavírus (Artigos e entrevistas). Trad.: Odorico Leal. São Paulo: Companhia das Letras, 2020 .

IDEOLOGIA. In: DICIONÁRIO direito. [201-?]. Disponível em: https://dicionariodireito.com.br/ideologia. Acesso em: 1 abr. 2021.

INSTITUTO NACIONAL DE ESTUDOS E PESQUISAS EDUCACIONAIS ANÍSIO TEIXEIRA. Página do participante: População do Brasil 2021 atualizada - 212M. 24 dez. 2020. Disponível em: https://paginadoparticipante.com/populacao-do-brasil/. Acesso em: 3 abr. 2021.

LENZI, Tié. O que é democracia? 20 set. 2019. Disponível em: https://www.todapolitica.com/democracia/. Acesso em: 2 abr. 2021. 
MAGENTA, Matheus. Afinal, Brasil vacina pouco ou muito? Confira 5 dados do ranking global. 8 abr. 2021. Disponível em: https://www.bbc.com/portuguese/brasil-56680167.

Acesso em: 9 abr. 2021.

MEDINA, José Miguel Garcia. Constituição Federal comentada. São Paulo: Revista dos Tribunais, 2012.

MURTA, Antônio Carlos Diniz; RAPOSO, Nilo Augusto Remigio. Autonomia Federativa no Enfrentamento do Coronavírus. In: REZENDE, Elcio Nacur et al. (orgs.). Implicações jurídicas do Covid-19. Belo Horizonte: Arraes Editores, 2020. p. 13-34.

ORGANIZAÇÃO DOS ESTADOS AMERICANOS. Comissão Interamericana de Direitos Humanos. Resolução no 1/2020: Pandemia e Direitos Humanos nas Américas. Disponível em: https://www.oas.org/pt/cidh/decisiones/pdf/Resolucao-1-20-pt.pdf. Acesso em: 12 abr. 2021.

ORGANIZAÇÃ̃ MUNDIAL DA SAÚDE. Constituição da Organização Mundial da Saúde. 1946. Disponível em: http://www.direitoshumanos.usp.br/index.php/OMSOrganiza\%C3\%A7\%C3\% A3o-Mundial-da-Sa\%C3\%BAde/constituicao-da-organizacaomundial-da-saude-omswho.html. Acesso em: 2 abr. 2021.

PORFÍRIO, Francisco. Democracia. 2021. Disponível em: https://brasilescola.uol.com.br/sociologia/democracia.htm. Acesso em: 1 abr. 2021.

REZENDE, Elcio Nacur (et al). Implicações jurídicas do Covid-19. Belo Horizonte, Arraes Editores: 2020.

SAMPAIO, José Adércio L. Teoria da Constituição e dos direitos fundamentais. Belo Horizonte: Del Rey, 2013.

SANÍN-RESTREPO, Ricardo; ARAÚJO, Marinella M. A teoria da encriptação do poder: itinerário de uma ideia. Revista da Faculdade Mineira de Direito, v. 23, n. 45, p. 1-17, 2020.

STF conclui julgamento de MPs que regulamentam competência para impor restrições durante pandemia. Notícias STF, 6 mai. 2020. Disponível em:

http://stf.jus.br/portal/cms/verNoticiaDetalhe.asp?idConteudo=442816\#. Acesso em: 2 abr. 2021.

TEPE, Markus et al. Pandemic Balancing Acts: Early COVID-19 lockdown changes how Germans trade off lives and weigh constitutional powers. 2020. Disponível em: https://osf.io/geu52/download?format=pdf. Acesso em: 28 dez. 2020.

VELOSO BRASIL, Sérgio Augusto. Estado, violência, guerra e "estado de exceção": uma visão freudiana em lição de Anthony Sampson. In: MORAIS, Clarice Paiva; SOUZA, Lívia Maria Cruz; SOUTO, Luana Martins (orgs.). Vieses constitucionais: reflexões à luz do constitucionalismo democrático. Curitiba: CRV, 2020. 
WORLD HEALTH ORGANIZATION. WHO Coronavirus (COVID-19) Dashboard. 12 abr. 2021. Disponível em: https://covid19.who.int/. Acesso em: 13 abr. 2021.

ZANATTA, Loris. El populismo. Trad. Federico Villegas. Buenos Aires: Katz, 2014. 